TP Periodica Polytechnica

42(2), pp. 97-102, 2014

DOI: $10.3311 /$ PPtr. 7225

Creative Commons Attribution (i)

RESEARCH ARTICLE

\section{Supporting Demand Planning Process with Walsh-Fourier Based Techniques}

\author{
Krisztián Bóna / Balázs Lénárt
}

RECEIVED 15 DECEMBER 2013

\begin{abstract}
The demand planning is one of the most frequented topics in logistics planning within the supply chain management. The prediction of future demand is a very important phase in the enterprise resource planning in point of view of supporting other planning functions (e.g. production planning, material requirements planning etc.). The statistical forecasting is the first step in this very complex process. The effectiveness of the traditional forecasting methods is very variable in the real economic environment. The dyadic harmonic analysis is a new stream and alternative solution to recognize and understand the behavior of the economical time series.
\end{abstract}

\section{Keywords \\ demand planning $\cdot$ forecast $\cdot$ Walsh-Fourier}

\section{Introduction}

Demand planning has very strong connection to enterprise logistics planning and related areas. Demand planning generates the input data for other planning areas, which are mainly used in strategic and operative process planning (Tadic and Zecevic, 2012; Mrówczyńska, 2012; Vorosmarty and Dobos, 2013; Markovic et. al., 2013). These data are increasing the competitiveness of companies in the future. For example:

- the operative production planning creates the production time schedule of the products,

- the resource planning at manufacturing is responsible for the optimal quantity and composition of raw material inventories for human resource and machines,

- the finance and budget planning gives the stable financial base of the future operation, and so on.

On all of these areas precise demand planning is a must and if the result is inaccurate, then the operation of the enterprise will be inefficient and instable. Inaccuracy generates uncertainly in the supply chains and results high level of inventories on all levels, so it is important to generate more accurate forecasts of demand accordingly.

Based on many international researches the basics of the modern demand planning systems are the efficient statistical algorithms (Hamzaçebi et al., 2009; Kabashkin, 2012; Jha et. al., 2013), and the automatization of the planning process (Haberleitner et al., 2010). Beside the known methods a new technique is getting used in this area, which is the WalshFourier (dyadic) analysis. In this article the usability of this technique will be investigated in the point of view of demand planning. In our opinion - in the future - dyadic analysis could give a very good basis of the development of demand planning systems.

\section{Demand Planning}

Fig. 1 shows the main phases of the operative demand planning process and the main outputs of the phases. The demand planning is more complex than forecasting, because it is only one step in the five step circular process. The connection point 


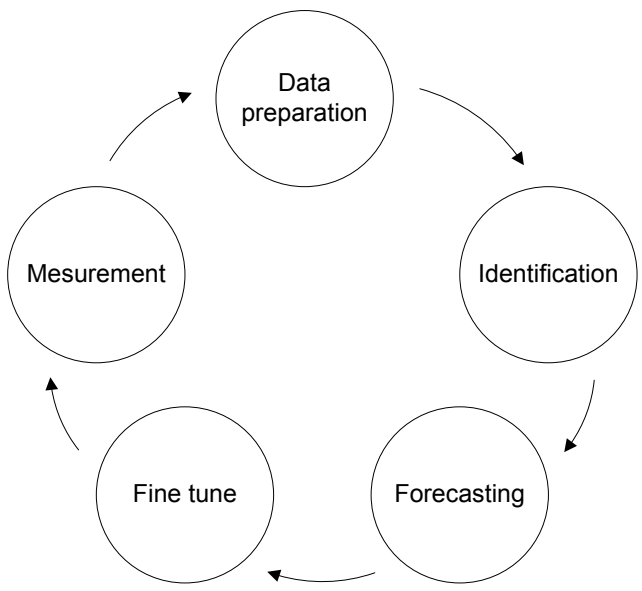

Fig. 1. Operative demand planning

to ERP systems and to other enterprise planning systems is the data preparation.

In this phase filtering of marketing and other commercial activities is needed. These functions can give some really adequate additional information about the future demand. The second phase is the identification. In this section the goal is to understand, how the real demand behaves. We would like to detect the main statistical properties of the demand. Based on this properties we would like to find, which statistical models are able to support the forecasting. The next step is to parameterize the selected model and make the prediction. Based on the practical experience to find the correct set of parameters is the most difficult problem at the moment. If statistical model is good parameterized, then accurate prediction can be performed. In the next step in the fine tune phase the demand planner applies some corrections based on other commercial and marketing information, because the classical statistical models cannot take account of these information directly. The output of this phase is the fully agreed demand plan. This plan is the input of other enterprise planning functions (for example production planning, planning of inventories and so on). The last step is the measurement, which gives the feedback for the whole demand planning process. It is possible to use different kind of key performance indicators, which are able to measure the efficiency of the planning. The main groups of the methods are (Chatfield, 1992; Armstrong and Collopy, 1992):

- measurement based on the deviance (e.g. MAPE),

- relative measurement (e.g. MRAE), and so on.

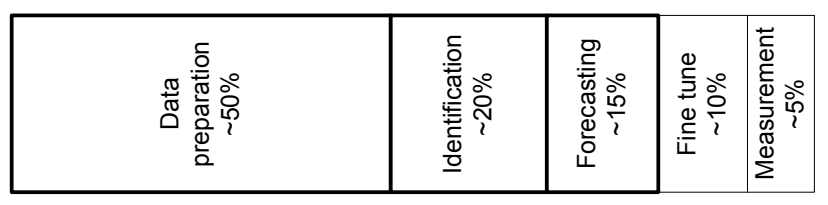

Fig. 2. Time appropriation of the demand planning process
Fig. 2 shows the time appropriation of the demand planning process in the percentage of total process lead time. Based on wide industrial experience it is visible that the total share of the first three phases are very high. In aggregate, approximately it takes $85 \%$ of the total process and the widest task is the data preparation. The concrete time appropriation is depended on the number of SKUs (stock keeping unit) in the master data. In a moderate sized SKU volume the mean of the time appropriation is approximately 3 or 4 hours in a workday. The estimated maximum value of time appropriation may be 5 or 6 hours. It is clear, that the development of the methodology in these phases is very important to achieve increased efficiency in planning.

In the last few decade several method was developed to reach the above mentioned goal, but still new fields are unexplored. In these days we need a method which is fast and fits to computer computation. In our case it is Walsh-Fourier method and we investigated that this new method would be capable to analyze and prepare time series as well as to produce forecast of a time series.

\section{Data representation}

The first development areas of Walsh-Fourier method are on the area of data preparation, model identification and forecasting.

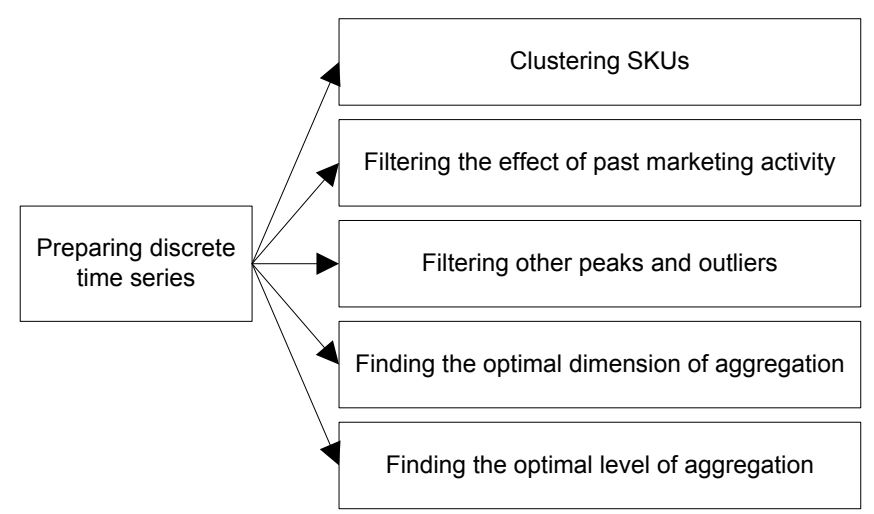

Fig. 3. Preparing discrete time series

Preparing time series, what is the input of the identification and forecasting is not a trivial task. Basically, the main goal is to generate the SKU based prediction, but it is very difficult if the real time series is sporadic or incomplete (Michelberger et al., 2001). Because of this reasons "clusters of data" based on the properties of the time must be created. For example: good predictable, noisy, very noisy, incomplete and so on. It is possible to apply various techniques (Hernández and Stolfo, 1998) to clean and repair the demand data (Fig. 3).

One technique is for example filtering the effects of past marketing activities, which influences the real demand. About marketing and commercial activities information is available, but about other peaks usually not, so there is real (residual) noise in the demand data. 


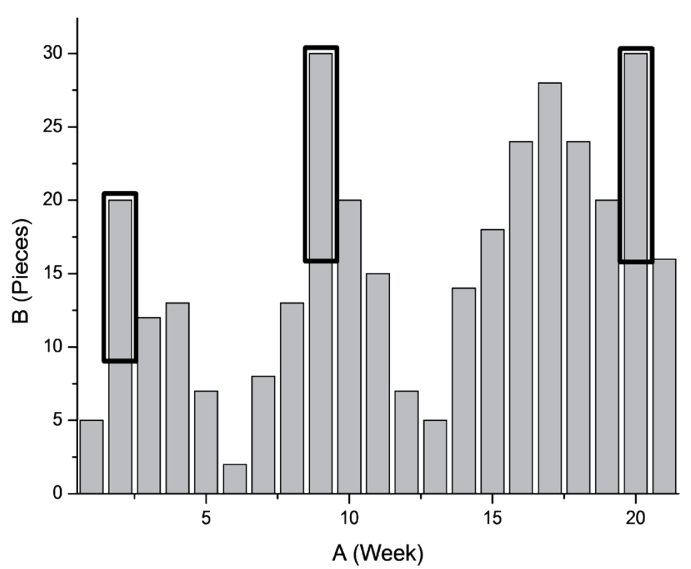

(a)

Fig. 4. Outliers (a) and sporadic (b) time series

Another technique is the data aggregation, which we can cover the failures and problems in the demand data with. In connection to this the main problem is finding the optimal dimensions and levels of data aggregation.

There are two cases to reach the optimal data set of the discrete time series of SKU-s, towards the high accurate of forecasting. The first is if in the time series has some direct outliers and the second is if the time series lack of data (this is the so called sporadic time series) which is shown on Fig. 4. The filtering and the completion of data are two areas of the possibilities, where the strengths of dyadic analysis in the data preparation can be used, as an analogy of satellite image restoration, recognition and error correction of sampled images.

Aggregation is a multi-criteria optimization problem. For example the first dimension is the aggregation deepness of data in the supply network. The result will be better if the aggregation is as near as it is possible to the real demand. The second dimension is the applied time slots of aggregation (for example daily, weekly, monthly based thinking). The third dimension is the marketing channel view (for example aggregation for the direct distribution, HORECA, wholesaler, retail channel, or all inclusive).

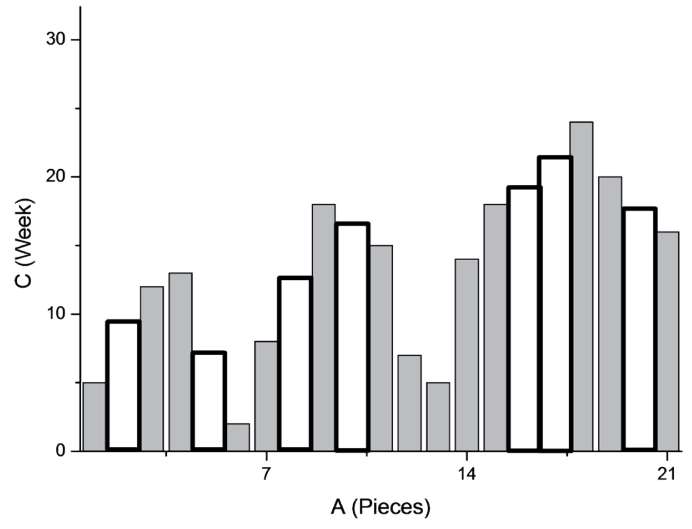

(b)
Other possibility is the further aggregation of multiple SKU time series (Fig. 5). If other methods are inefficient, then it can be create aggregated time series of SKU groups. It is possible to apply it together with the data filtering and completion too. The main question in this case is that there is more possible solution of aggregation, but which is the best grouping of SKUs? The target function of the SKU collection may be the maximization of the fitting accuracy of applied statistical model. The above mentioned findings are the most important aspects of data preparation problems.

\section{Identification and forecasting}

In the identification and forecasting phase the input is the prepared discrete time series.

Next important steps are to determine the forecasting model, calculate the correct parameters, and generate the prediction.

Fig. 6 shows the applied techniques, which we can answer these questions with, and development options are presented, where the usage of dyadic analysis is feasible.

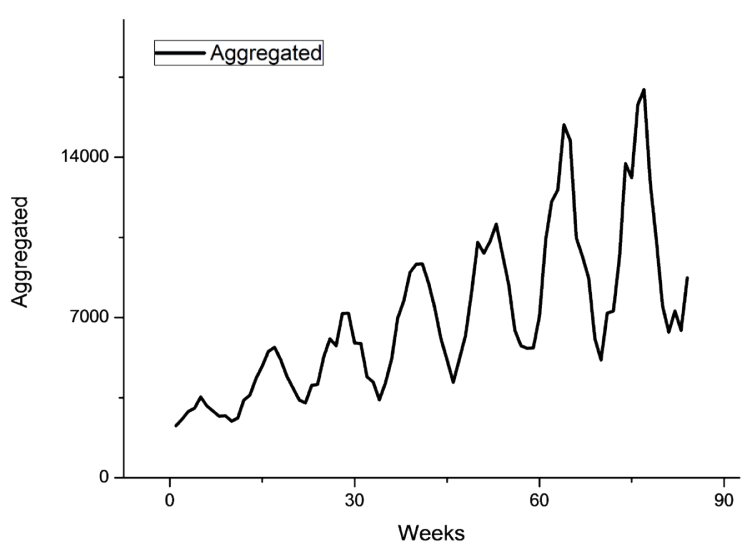

Fig. 5. Aggregation of SKUs 


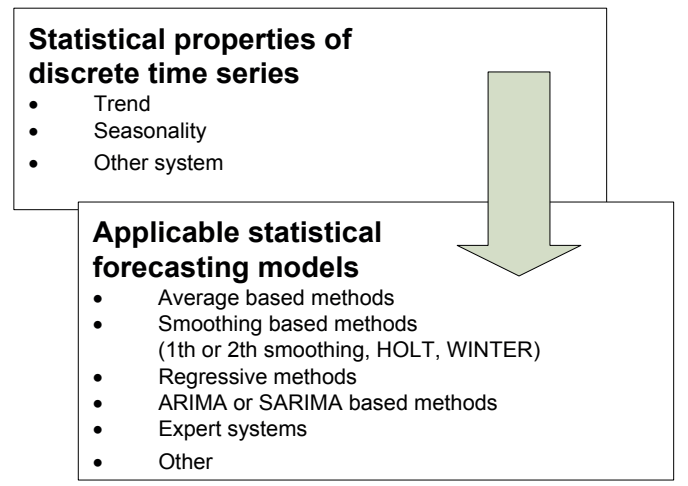

Fig. 6. Forecasting technics

The efficiency of applicable forecasting models is very variable in the practice. One of the main reasons is that the recognition of the statistical properties of time series is very inaccurate. There is very short time to accomplish the examination and this examination does not work automatically. There are two very important properties of the time series: trend, and seasonality. The detection of the additive or multiplicative trend process is usually answerable, but the detection of seasonality is not a trivial question. In case of economical time series we usually can suppose yearly seasonality. Depending on the applied time aggregation it can be 365 days or 52 weeks or 12 months. The detection must work automatically in the practice, because the planners haven't got enough time to the examinations. Because of this reason, the application of dyadic analysis may be a breakout point, which we can detect the periodicity of the examined time series with. After the detection of the statistical properties the next step is the transformation of the time series.

For example, in this phase the trend process and the seasonality in the time series are known. The application of normal and seasonal difference is very important, because before the application of the classical forecasting models steady state time series have to be created. The main reason of differencing is the filtering of trend and season effect. These differenced time series give the basis of the further statistical modeling. Interesting question is the optimal deepness of the time series differencing. There are rules, which are laid down by Box and Jenkins (Box and Jenkins, 1970). They have said, the maximum deepness of differencing in case of normal difference is two and in case of seasonal difference is one. Based on this, there are six combinations of differenced time series, which can determine the applicable forecasting models.

The last step of the identification is the selection of the applicable model for the forecasting. For example, in case of ARIMA models the starting points are the autocorrelation (ACF) and the partial autocorrelation functions (PACF) of the differenced time series. ARIMA models are the so called autoregressive integrated moving average models. Based on ACF and PACF functions is not easy to tell, which the adequate ARIMA models for forecasting are (Péter et al., 1984; Péter and Korcsog, 1986).
The output of the identification is the ARIMA operator equation, which contains the necessary AR and MA parameters in dependence on the normal and seasonal difference. At the moment, there are experience based algorithms only. The process is described as follows: We have to examine the shape of the above mentioned functions and we have to determine the main properties of the functions with some tests (cutoff test, average lag count test and so on).

With this method, the characteristics of the functions (for example: cutoff, slowly or exponential) can be determined (Tran et. al, 2004; Dobos and Tallos, 2013) and the AR and MA parameters in case of the normal, and the season difference can be estimated. These tests are very instable and very easy to influence. Because of these reasons fail detections are very frequent. In this point the question is how is it possible to use the beneficial properties of the dyadic analysis in favor of the exact calculation of AR and MA parameters based on the approximation of autocorrelation functions.

The adequate model identification is followed by the parametrization of the recognized model. In the ARIMA modeling the number of autoregressive and moving average parameters depending on the applied operator equation. After solving the operator equation we get the generator equation, which can be used for forecasting, but the parameters of the model are unknown. The precise calculation of these parameters is very important, because the generator equation is the basis of the forecasting. If these parameters are inaccurate, then the forecast become inaccurate too. The practical solution of this problem is the fitting of the generator equation to the original time series, based on the minimizing of error function $(\mathrm{e}(\mathrm{t}))$. The best fitting is if the error function is zero, but it is nice to have in case of a stochastic process. It is possible to use various techniques to calculate the unknown parameters. There are two applied techniques in the practice, the maximum likelihood estimation and the least squares method. In most cases it is very complicated and very slow to get these parameters in the practice, especially if the planner must generate the forecast for all of the SKU-s. At this point the question arises: Is it possible to increase the precision of fitting by application of "Walsh-Fourier thinking"?

\section{Walsh-Fourier analysis}

The basis of frequency domain (Fourier) analysis for time series is the spectral representation theorem for stationary processes. The observed time series must be stationary, it means that it must have a constant mean level. In the classical Fourier analysis the spectral representation theorem says that we may think of a stationary time series as being formed by the random superposition of sine and cosine waveforms. The same basic ideas are employed in Walsh-Fourier analysis (Stoffer, 1991); however, these functions are square waveforms that take on only two values, +1 and -1 . Since the Walsh functions are aperiodic, the value $\mathrm{t}$ in the notation $W\left(t, \lambda_{n}\right)$ cannot be called 
frequency as in the case of the periodic sinusoids, we use the term sequency to describe generalized frequency.

Let $X(0), X(1), \ldots, X(N-1)$ represent time series data. We propose that a time series is the superposition of Walsh functions at various sequences,

$$
X(t)=\sum_{n=1}^{q} A_{n} \cdot W\left(t, \lambda_{n}\right)
$$

where functions $W\left(t, \lambda_{n}\right)$ are Walsh functions and the $A_{n}$ 's are mutually uncorrelated mean-zero random variables with $\operatorname{var}\left\{A_{n}\right\}=\sigma_{n}^{2}$. In our current research two forecasting methods are being developed based on Walsh-Fourier analysis. The first method is based on cycle and trend detection (Walsh-cycledetection), the second is based on linear regression of the $A_{n}$ coefficient vector (Walsh-Linear).

\section{Results}

In the current paper two time series is being investigated: an ideal sinusoidal series and the same dataset with some random noise. The length of time series is 80 weeks and the first 64 datum is being used for fitting data the second 16 data is for statistical analysis. For the analysis the mean absolute error (MAE), median of absolute error (MdAE), mean squared error (MSE) and root mean squared error (RMSE) is being used. In case to compare the newly developed algorithms to traditional forecasting methods pre-identified ARIMA and SARIMA models were being used. As a result on a sinusoidal time series all methods perform well, which is shown on Figure 7.

The fitting of Fourier based solution (Walsh-Linear) is perfect which is caused by the linear trend and the periodicity of the original time series. The statistical results are being presented in Table 1.

When random noise on the same time series is being applied the performance of these algorithms drastically drops (Figure 8).

As a result it can be seen that on this noisy dataset traditional Box-Jenkins models perform worse than the experimental Walsh-Fourier based extrapolation (see Table 2). It is clear
Tab. 1. Statistical results of "ideal" time series

\begin{tabular}{lrrrr}
\hline & MAE & MdAE & \multicolumn{1}{c}{ MSE } & RMSE \\
\hline $\begin{array}{l}\text { Walsh-Cycle- } \\
\text { detection }\end{array}$ & 854 & 780 & 897387 & 947 \\
Walsh-Linear & & & & \\
ARIMA(2,1,2) & 1729 & 2258 & 3822489 & 1955 \\
SARIMA $(2,1,2)$ & 838 & 968 & 946861 & 973 \\
$(1,1,1)$ & & & & \\
\hline
\end{tabular}

Tab. 2. Statistical results of "noisy" time series

\begin{tabular}{lcccr}
\hline & MAE & MdAE & MSE & RMSE \\
\hline $\begin{array}{l}\text { Walsh-Cycle- } \\
\text { detection }\end{array}$ & 2690 & 2602 & 8932942 & 2989 \\
$\begin{array}{l}\text { Walsh-Linear } \\
\text { ARIMA(2,1,2) }\end{array}$ & 6795 & 5417 & 71613792 & 8462 \\
$\begin{array}{l}\text { SARIMA(2,1,2) } \\
(1,1,1)\end{array}$ & 9354 & 3026 & 41066934 & 6408 \\
\hline
\end{tabular}

that it can be getting better results with ARIMA models, but the focus is on the demonstration of usability of the new methods.

For better results we propose use data cleansing techniques. In the future the development of a Walsh-Fourier based data preparation method is planned.

\section{Summary}

In this paper the demand planning process was presented and some bottlenecks and difficulties were noticed. There are four main groups of the proposals in the demand planning, where the tools of dyadic analysis can help in the solving of mathematical problems. The first is the data cleansing, the second is the recognizing, the third is the optimization, and the fourth is the approximation. In this proposal four state-of-the-art forecasting techniques were compared. It was shown that the presented Walsh-Fourier based methods offer new opportunities for time series forecasting.

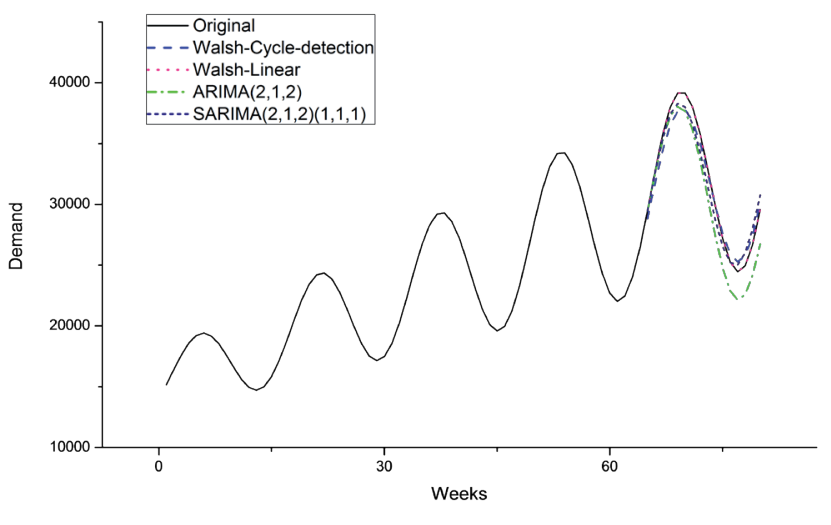

Fig. 7. Ideal time series

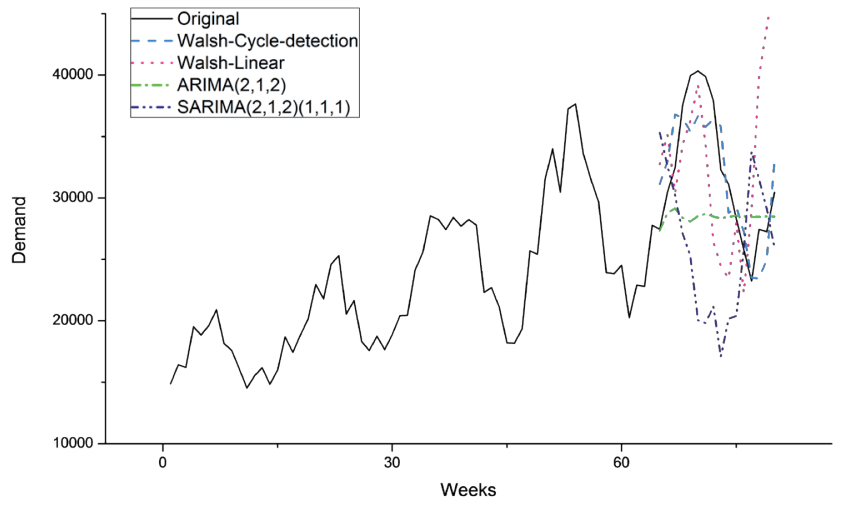

Fig. 8. Time series with random noise 


\section{Acknowledgement}

The authors would like to acknowledge the financial support of the TÁMOP-4.2.2.A-11/1/KONV-2012-0051 Research Program.

\section{References}

Armstrong J. S. and Collopy F. (1992) Error measures for generalizing about forecasting methods: Empirical comparisons. International Journal of Forecasting, 8 (1), pp. 69-80. DOI: 10.1016/0169-2070(92)90008-W

Box G. E. P. and Jenkins G. M. (1970) Time series analysis: Forecasting and control. San Francisco: Holden-Day.

Chatfield C. (1992) A commentary on error measures. International Journal of Forecasting, 8 (1), pp. 100-102. DOI: 10.1016/0169-2070(92)90011-W

Dobos I. and Tallos P. (2013) A Dynamic Input-Output Model with Renewable Resources. Central European Journal Of Operations Research, 21 (2), pp. 295-305. DOI: $10.1007 / \mathrm{s} 10100-011-0235-2$

Haberleitner H., Mexr H. and Taudes A. (2010) Implementation of a demand planning system using advance order information. International Journal of Production Economics, 128 (2), pp. 518-526. DOI: 10.1016/j.ijpe.2010.07.003

Hamzacebi C., Akay D. and Kutay F. (2009) Comparison of direct and iterative artificial neural network forecast approaches in multi-periodic time series forecasting. Expert Systems with Applications, 36 (2), pp. 3839-3844.

DOI: $10.1016 /$ j.eswa.2008.02.042

Hernández M. A. and Stolfo S. J. (1998) Real-world data is dirty: Data cleansing and the merge/purge problem. Data Mining and Knowledge Discovery, 2 (1), pp. 9-37. DOI: 10.1023/A:1009761603038

Jha K., Sinha N., Arkatkar S. S., Sarkar A. K. (2013) Modeling Growth Trend And Forecasting Techniques For Vehicular Population In India. International Journal for Traffic and Transport Engineering, 3 (2), pp. 139-158. DOI: $10.7708 /$ ijtte.2013.3(2).04
Kabashkin I. (2012) Freight Transport Logistics In The Baltic Sea Region. Regional Aspects. Transport and Telecommunication, 13 (1), pp. 33-50.

DOI: $10.2478 / \mathrm{v} 10244-012-0004-\mathrm{x}$

Michelberger P., Szeidl L. and Várlaki P., (2001) Applied process statistics and time-series analysis: [In Hungrian: Alkalmazott folyamatstatisztika és idősor-analizis.] Series of Apllied Matematics [In Hungarian: Alkalmazott matematika sorozat], Typotex, p. 390. ISBN 10 963-9132-44-6

Markovic G., Gasic M., Kolarevic M., Savkovic M., Marinkovic Z. (2013) Application of the MODIPROM method to the final solution of logistics centre location. Transport, 28 (4), pp. 341-351. DOI: $10.3846 / 16484142.2013 .864328$

Mrówczynska B., Łachacz K., Haniszewski T., Sładkowski A. (2012) A comparison of forecasting the results of road transportation needs. Transport, 27 (1), pp. 73-78. DOI: $10.3846 / 16484142.2012 .666763$

Péter T. and Korcsog A. (1986) Input output process examination of loading system periodicity [In Hungarian: Rakodási rendszerek input-output folyamatainak jellemzö periodicitásának vizsgálata] . Automation [In Hungarian: Automatizálás], 19 (6), pp. 26-33.

Péter T., Prezenszki J. and Várlaki P. (1984) Examination of loading system dynamics [In Hungarian: A rakodási rendszerek dinamikájának vizsgálata]. Scientific Transport Review [In Hungarian: Közlekedéstudományi Szemle], 53 (5), pp. 208-219.

Morettin P. A. (1991) Walsh-Fourier Analysis and its Statistical Applications. Journal of the American Statistical Association, 86 (414), pp. $483-485$. DOI: $10.2307 / 2290598$

Tadic S. and Zecevic S. (2012) Development Of Intermodal Transport And Logistics In Serbia. 